Tropical Journal of Pharmaceutical Research February 2017; 16 (2): 453-462

ISSN: $1596-5996$ (print); 1596-9827 (electronic) (c) Pharmacotherapy Group, Faculty of Pharmacy, University of Benin, Benin City, 300001 Nigeria.

All rights reserved.

\title{
Physical training improves cardiopulmonary functional capacity and increases cytokine IL-10 levels in individuals with Chagas disease
}

\author{
Wania S Lopes ${ }^{1}$, Érika C Ferreira ${ }^{2}$, Suelen S Silva ${ }^{3}$, Fernanda Tomiotto- \\ Pellissier $^{3}$, Ivete C Costa ${ }^{3}$, Wander R Pavanelli ${ }^{3}$, Silvana M Araújo ${ }^{4}$ and Mônica \\ L Gomes ${ }^{4 *}$ \\ ${ }^{1}$ Post-Graduate Program in Health Sciences, Department of Health Sciences, ${ }^{2}$ Department of Statistics, State University of \\ Maringa, ${ }^{3}$ Department of Pathology Science, Center of Biological Sciences, State University of Londrina, Londrina, ${ }^{4}$ Chagas \\ Disease Laboratory, Human Parasitology, Department of Basic Health Sciences, State University of Maringa, Paraná, Brasil
}

*For correspondence: Email: mlgomes@uem.br; monicaluciagomes@gmail.com; Tel/Fax: +55 (44) 3011-8988/3011-4860

\begin{abstract}
Purpose: To evaluate cardiopulmonary functional capacity and the production of cytokines in patients with and without Chagas disease, and with and without hypertension, after short and long-term exercise.

Methods: In a case-controlled study, 56 participants who attended the Chagas Disease Laboratory at the State University of Maringa (LDC/UEM) and Basic Health Units (UBS) in Maringa that agreed to participate. The participants were divided into the following groups: 16 with Chagas disease (CHD group), 21 with systemic arterial hypertension (SAH group) and 19 normal individuals without these morbidities (NI group). Each participant performed the 6-min walk test (6MWT), and a 12-week physical training program. Pro-inflammatory and anti-inflammatory cytokines were measured before and after physical training.

Results: The CHD group presented good performance in the 6MWT, with no significant differences in distance traveled or perceived exertion $(p>0.05)$ compared with the NI group. After physical training, the 6MWT results were significantly better, with significant decreases in systolic and diastolic blood pressure, in the SAH group $(p=0.0409$; and $p=0.0377$, respectively) and $\mathrm{Nl}$ group $(p=0.0180$; and $p$ $=0.0431$, respectively) and a significant increase in the levels of the anti-inflammatory cytokine interleukin-10 (IL-10; $p<0.05)$ in all three groups. The NI group exhibited a significant increase $(p<$ 0.05 ) in the serum levels of the pro-inflammatory cytokines IL-6, IL-17 and tumor necrosis factor (all $p<$ 0.05).

Conclusion: All of the participants presented improvements in cardiopulmonary functional capacity and good prognosis, indicating the protective effect of IL-10 production and the benefits of physical training.
\end{abstract}

Keywords: Chagas disease, Six-minute walk test, Physical training, Cytokines, Cardiopulmonary function capacity, Hypertension

Tropical Journal of Pharmaceutical Research is indexed by Science Citation Index (SciSearch), Scopus, International Pharmaceutical Abstract, Chemical Abstracts, Embase, Index Copernicus, EBSCO, African Index Medicus, JournalSeek, Journal Citation Reports/Science Edition, Directory of Open Access Journals (DOAJ), African Journal Online, Bioline International, Open-J-Gate and Pharmacy Abstracts

\section{INTRODUCTION}

Latin America, and specifically, Brazil still have many chronic carriers of Chagas disease who need proper medical care [1], but these individuals face psychosocial barriers for to diagnosis, treatment, and disease control, and have limited availability of resources or political support [1]. Thirty percent of Chagas disease 
cases present cardiac involvement [2]. Patient's daily work activities can become limited, thus contributing to a progressive decline in functional capacity and quality of life [3]. In addition to manifestations that are inherent to this disease, it is also associate with other ailments, including systemic arterial hypertension (SAH) and diabetes mellitus [4].

The mechanisms of the pathogenesis of Chagas disease are not well understood. There is a direct relationship between the persistence of the parasite in the host, the host's immune response, and the genetic variability of the host [5]. Among the host-related factors, the immune response has aroused special interest, with an emphasis on the regulatory role of cytokines [6].

Alternative approaches to intervention, such as physical exercise, may increase the functional capacity of affected organs and improve the quality of life of patients with Chagas disease and hypertension. Studies of women with Chagas disease $[7,8]$ reported that short-term aerobic exercise increased physical exertion tolerance [7] and had beneficial effects on systolic blood pressure (SBP), diastolic blood pressure (DBP) and heart rate (HR) [8].

Some studies $[6,9]$ have also reported that the intensity, duration, and frequency of physical activity play a key role in determining immune function, which can either increase or decrease the response to infection. Long-term physical training, in turn, can increase of antiinflammatory cytokines, especially interleukin IL-10 and IL-13 [6].

Regular moderate-intensity exercise can decrease the occurrence of infection and intense exercise reduces the susceptibility to infection [6], a phenomenon that is related to enhanced activity of the inflammatory response. The response to exercise in patients with heart disease of different etiologies, has been the subject of many investigations [10], but assessments of cardiopulmonary functional capacity and the immune response in individuals with Chagas disease are rare.

The 6-min walk test (6MWT) is the most used method for evaluating submaximal exertion, because of its ability to measure the individual's functional capacity by the simple act of walking. The present study investigated the role of exercise in the immune response in individuals, with Chagas disease compared with individuals with $\mathrm{SAH}$ and healthy individuals without these morbidities.

\section{EXPERIMENTAL}

\section{Ethical consideration}

This study was approved by the Committee for Ethics in Research with Human Beings at State University of Maringa (CAAE 0397.0.093.00010), and international guidelines for human studies were followed [11]. The participants signed an informed consent form that was approved by the Standing Committee for Ethics in Research with Human Beings (COPEP/UEM).

\section{Study population}

Fifty-six volunteers who attended the Chagas Disease Laboratory at the State University of Maringa (LDC/UEM) and Basic Health Units in Maringa were recruited for the study. The inclusion criteria were the following: individuals with Chagas disease (CHD group) without heart failure or with mild or moderate heart failure (New York Heart Association [NYHA] functional class I or II), individuals with mild to moderate systemic arterial hypertension (SAH - group), and normal individuals ( $\mathrm{NI}$ - group) without these morbidities, and with stable clinical conditions. Participants of both genders, were included (3580 old). The exclusion criteria were the following: severe hypertension (SBP > $180 \mathrm{mmHg}$ and $\mathrm{DBP}>110 \mathrm{mmHg}$ ), decompensated diabetes mellitus, NYHA functional class III or IV congestive heart failure, cardiac pacemaker, chronic renal failure, pulmonary or pleural disease, musculoskeletal limitations or any other condition that would affect the ability to perform the functional tests.

Participants were assessed for Chagas disease using indirect immunofluorescence and enzyme linked immunosorbent assay at the Teaching and Research Laboratory in Clinical Analysis (Laboratório de Ensino e Pesquisa em Análises Clínicas da Universidade Estadual de Maringá LEPAC/UEM). They were also assessed by a cardiologist to perform treadmill exercise testing and determine the maximal and submaximal HR and intensity of physical exercise.

The participants were divided into three groups: CHD $(n=16), \operatorname{SAH}(n=21)$, and NI $(n=19)$. The demographic characteristics and level of physical activity of the 56 participants are listed in Table 1. The mean age was $63.2 \pm 8.4$ years old and $75 \%$ the participants were female. No significant difference in mean age was found between the $\mathrm{CHD}$ group and the other groups. No significant difference in the proportion of men was found between groups $(p>0.05)$. 
Table 1: Demographics and level of physical activity of the 56 participants in CHD, SAH and NI groups subjected to the 6MWT and 12-week physical training program

\begin{tabular}{lcccccc}
\hline Variable & \multicolumn{2}{c}{ CHD $(\boldsymbol{n}=\mathbf{1 6})$} & \multicolumn{2}{c}{ SAH $(\boldsymbol{n}=\mathbf{2 1})$} & \multicolumn{2}{c}{ NI $(\boldsymbol{n}=\mathbf{1 9})$} \\
\hline Age & Mean & \pm SD & Mean & \pm SD & Mean & \pm SD \\
\hline (years) & 63.9 & 7.0 & 66.2 & 6.8 & 60.1 & 7.9 \\
& & & & & & \\
Gender & $\boldsymbol{n}$ & $\%$ & $\boldsymbol{n}$ & $\%$ & $\boldsymbol{n}$ & $\%$ \\
Male* $^{*}$ & 4 & 25.0 & 1 & 4.8 & 2 & 10.5 \\
Female & 12 & 75.0 & 20 & 95.2 & 17 & 89.5
\end{tabular}

\section{Sedentary lifestyle}

\begin{tabular}{lcccccc} 
Yes & 6 & 37.5 & 0 & 0.0 & 0 & 0.0 \\
No & 10 & 62.5 & 21 & 100.0 & 19 & 100.0 \\
\hline
\end{tabular}

CHD: Chagas disease, SAH: systemic arterial hypertension, NI: normal individuals, $6 \mathrm{MWT}$ : 6-min walk test. ${ }^{*} p>$ 0.05

\section{Six-minute walk test}

The 6MWT was performed according to the recommendations of the American Thoracic Association [12]. The 6MWT was always performed in the morning, between 8:00 AM and 11:00 AM. The participants were instructed to walk as fast as possible for $6 \mathrm{~min}$, without running, on a $30 \mathrm{-m}$ long flat surface, without barriers traffic, from other people. The surface was marked every $1 \mathrm{~m}$. Before starting the test, the volunteers were instructed about performing the test and its risks and benefits. All of the subjects were informed by the therapist regarding the elapsed time and received standardized verbal encouragement every minute. The intensity of verbal encouragement has been shown to affect the total distance traveled (i.e., the distance increases with more frequent and intense verbal encouragement) [12].

The participants were allowed to slow down, rest, or stop the test if necessary. If the participant stopped to rest, them they were instructed to resume walking as quickly as possible. If the participant stopped walking for some reason, then participant was placed in a chair and instructed to resume walking when possible [12]. After the end of the 6MWT, the distance traveled (in meters) and blood oxygen saturation were determined. The participant's the subjective perceived exertion, was also assessed using the Borg scale: 0 (no exertion) to 10 (extreme exertion) [13].

The 6MWT was immediately discontinued if the participant experienced precordial chest pain, intolerable dyspnea, $\mathrm{O}_{2}$ saturation $\leq 85 \%$, muscle cramps, limping gait, malaise dizziness, or pallor.

\section{Determination of cytokine and nitric oxide levels}

The serum levels of cytokines were analyzed using a cytometric bead array (CBA) and determined according to the kit's instructions (CBA Human Th1/Th2/Th17 Becton Dickinson) using a ACCURI C5 device (Becton Dickinson). The cytometry data were analyzed using "FCAP Array, 3.0.3, software (Soft Flow Hungary, Ltd."). Cytokine concentrations are expressed as pg/ml. We excluded participants whose cytokine concentrations were undetectable by the kit. Proinflammatory cytokines [(IL-2, IL-6, IL-17, tumor necrosis factor-alpha (TNF- $\alpha$ ), interferon-gamma (IF-y)], inflammatory cytokines (IL-4, IL-10) and nitric oxide (NO), were are evaluated at 0,6 and 12 weeks (T0, T6, and T12 weeks) in 12 participants in the CHD group, 13 participants in the $\mathrm{SAH}$ group and 14 participants in NI group. Nitrite levels were used to estimate serum NO levels according to Panis et al [14].

\section{Physical training program}

After performing the 6MWT and measuring cytokine levels at the beginning of the study (TO), the participants performed a 12-week aerobic physical training program, three times per week on alternate days. The exercise was of moderate intensity $(70-80 \%$ of maximum HR), with a gradual increase in duration each session up to a maximum of $1 \mathrm{~h}$, based on the clinical condition of the patient.

Initially, the participants performed muscle warmups with active stretching of the upper and lower 
limb, for $5 \mathrm{~min}$, progressing to $10 \mathrm{~min}$ in the third training session. The aerobic phase of the exercise program was performed by walking for $15 \mathrm{~min}$, which progressively increased to $20 \mathrm{~min}$ in the second session and then to $30 \mathrm{~min}$ in the third session. At the end of each session, the participant was allowed to cool down, followed by 10-min relaxation. The physical exercise program was conducted by a trained professional, in the morning, and outdoors, in a flat and shaded location.

Systolic blood pressure (SBP), diastolic blood pressure (DBP), heart rate (HR) and blood oxygen saturation $\left(\mathrm{SpO}_{2}\right)$, were evaluated at the beginning of the study (T0), and after 6 weeks (T6) and 12 weeks (T12) of physical training. Measurements were taken both pre- and postexertion. The SBP and DBP were measured on the left arm while each participant was in a sitting position. The measurements were taken using an indirect method and auscultation technique using a stethoscope and previously calibrated sphygmomanometer (Becton Dickinson). Heart rate was measured manually by palpation of the radial artery by a single evaluator. $\mathrm{SpO}_{2}$ was measured using a pulse oximeter.

\section{Statistical analysis}

Intra-group differences at T0, T6 and T12 were determined using the Wilcoxon test. Differences between the $\mathrm{CHD}, \mathrm{SAH}$, and $\mathrm{NI}$ groups were compared using analysis of variance (ANOVA). Cytokine levels at T0, T6 and T12 were evaluated by one-way ANOVA, followed by Tukey's multiple-comparison test. The data were analyzed using Prism 5.0 software (GraphPad, San Diego, CA, USA). The level of significance was $5 \%$.

\section{RESULTS}

Table 2 shows the distance traveled in the $6 \mathrm{MWT}$, at the beginning of the study, and after 12 weeks of physical training, which was not significantly different between groups. Intragroup comparisons revealed a significant difference in distance traveled between the beginning of the study and after 12 weeks of physical training. All of the participants were able to complete the 6MWT without interruption.

With regard to perceived exertion, indicated by the modified Borg scale, $43.7 \%$ of the participants in the CHD group, $47.6 \%$ of the participants in the SAH group, and $52.6 \%$ of the participants in the $\mathrm{NI}$ group reported no physical exertion (Borg scale $=0$ ) at the end of the 6MWT at the beginning of the study. None of the participants reported maximum exertion (Borg scale $=10)$ the $6 \mathrm{MWT}$ at either the beginning of the study or after 12 weeks of physical training, with no significant inter- or intra- group differences (Table 2).

At T0 the beneficial effects of exercise were already evident. The $\mathrm{CHD}$ and $\mathrm{SAH}$ groups exhibited a significant decrease in SBP $(p=$ 0.0017 and $p=0.0190$, respectively), and significant increase in $\mathrm{HR}(p=0.00001$ and $p=$ 0.0048 respectively). The CHD and $\mathrm{NI}$ groups also presented significant improvements in oxygen saturation $(p=0.00005)$ (data not shown).

At T6 pre exertion, CHD group exhibited a significant improvement in oxygen saturation and the SAH group exhibited a significant decrease in SBP (6.7 mmHg) (Table 3).

Table 2: Distance traveled (in meters), and perceived exertion (according to the Borg scale) in participants with Chagas disease (CHD), and systemic arterial hypertension (SAH) and normal individuals (NI), in the 6-min walk test (6MWT) at the beginning of the study - 6MWT (1) and after the 12-week physical training - 6MWT (2).

\begin{tabular}{lccccccc}
\hline Variable & \multicolumn{2}{c}{ Group } & \multicolumn{2}{c}{$\begin{array}{c}\text { Beginning of } \\
\text { study } \\
\text { mean } \pm \text { SD }\end{array}$} & $\begin{array}{c}\text { After 12 weeks of } \\
\text { physical training } \\
\text { mean } \pm \text { SD }\end{array}$ & \\
\hline \multirow{2}{*}{$\begin{array}{l}\text { Distance in } \\
\text { 6MWT(m) }\end{array}$} & $\mathrm{CHD}$ & $(\boldsymbol{n}=16)$ & 584.2 & \pm 62.3 & 602.8 & \pm 60.6 & $0.0084^{*}$ \\
& $\mathrm{SAH}$ & $(\boldsymbol{n}=21)$ & 585.0 & \pm 75.6 & 610.5 & \pm 75.8 & $0.0011^{*}$ \\
& $\mathrm{NI}$ & $(\boldsymbol{n}=19)$ & 569.8 & \pm 72.5 & 595.6 & \pm 60.2 & $0.0023^{*}$ \\
& & & & & & & \\
Borg scale & $\mathrm{CHD}$ & $(\boldsymbol{n}=16)$ & 1.4 & \pm 1.8 & 1.4 & \pm 1.5 & 0.7532 \\
& $\mathrm{SAH}$ & $(\boldsymbol{n}=21)$ & 1.4 & \pm 1.5 & 2.0 & \pm 1.2 & 0.1415 \\
& $\mathrm{NI}$ & $(\boldsymbol{n}=19)$ & 1.5 & \pm 1.8 & 1.1 & \pm 1.2 & 0.2367 \\
\hline
\end{tabular}


Between T6 and T12, the CHD group presented significant decreases in pre- and post-exertion SBP and pre-exertion DBP, and the $\mathrm{NI}$ group presented significant decreases in post-exertion SBP and DBP (data not shown).

At T12, pre-exertion SBP significantly decreased in the CHD group $(6.8 \mathrm{mmHg})$, SAH group (10 $\mathrm{mmHg}$ ), and $\mathrm{NI}$ group (5.8 $\mathrm{mmHg}$; Table 3), and post-exertion SBP significantly decreased in the $\mathrm{SAH}$ group $(7.1 \mathrm{mmHg})$ and $\mathrm{NI}$ group $(5.2$ $\mathrm{mmHg}$; Table 4). Pre- and post-exertion DBP significantly decreased in the SAH and NI groups (Tables 3 and 4). Significant improvements in pre-exertion oxygen saturation were observed in the $\mathrm{CHD}$ and NI groups (Table 3).

Inter-group comparisons revealed a significant difference in SBP between the $\mathrm{NI}$ group and
CHD and SAH groups at T0, T6 and T12. A significant difference in DBP was observed between the CHD group and NI group at T0, T6, and T12. A significant difference in HR was observed between the $\mathrm{CHD}$ group and $\mathrm{SAH}$ group at T0, T6 and T12 (data not shown).

At T6, a significant increase in IL-10 levels was observed in the CHD group ( $p=0.0207$ Figure 1). Between $T 6$ and $T 12, I L-10$ levels increased in all three groups, which also occurred at T12 (CHD: $p=0.0022$; SAH: $p=0.0010$; NI: $p=$ $0.0015)$. Significant differences in the levels of IL2, IL-6, IL-17 and TNF - $\alpha$ were only observed in the NI group at T12 (Figure 1). In the CHD and SAH groups, IL-17 levels increased but not significantly. IFN-y levels were not significantly different between groups at T0, T6 or T12.

Table 3: Analysis of pre-exertion systolic blood pressure (SBP) and diastolic blood pressure (DBP), heart rate (HR) and oxygen saturation $\left(\mathrm{SpO}_{2}\right)$ in participants with Chagas disease (CHD), and systemic arterial hypertension (SAH) and normal individuals (NI) at T0, T6, and T12

\begin{tabular}{|c|c|c|c|c|c|c|c|c|c|}
\hline \multirow{2}{*}{ Group } & \multirow{2}{*}{$\begin{array}{c}\text { Pré-exertion } \\
\text { variable } \\
\text { SBP }\end{array}$} & \multicolumn{2}{|c|}{$\begin{array}{c}\text { T0 } \\
\text { (mean } \pm \text { SD) }\end{array}$} & \multicolumn{2}{|c|}{$\begin{array}{c}\text { T6 } \\
\text { (mean } \pm \text { SD) }\end{array}$} & \multirow{2}{*}{$\begin{array}{c}p \\
0.3454\end{array}$} & \multicolumn{2}{|c|}{$\begin{array}{c}\text { T12 } \\
\text { (mean } \pm \text { SD) }\end{array}$} & \multirow{2}{*}{$\begin{array}{c}\boldsymbol{P} \\
0.0366^{\star}\end{array}$} \\
\hline & & 130.6 & 16.1 & 128.8 & 11.5 & & 123.8 & 9.6 & \\
\hline \multirow{3}{*}{$\begin{array}{l}\text { CHD } \\
(n=16)\end{array}$} & DBP & 82.5 & 9.3 & 81.9 & 8.3 & 0.7150 & 78.8 & 7.2 & 0.1097 \\
\hline & HR & 67.1 & 11.9 & 68.1 & 7.9 & 0.6292 & 68.1 & 8.3 & 0.4412 \\
\hline & $\% \mathrm{SpO}_{2}$ & 96.9 & 1.5 & 97.3 & 1.1 & $0.0277^{*}$ & 97.3 & 1.0 & $0.0277^{*}$ \\
\hline \multirow{4}{*}{$\begin{array}{c}\text { SAH } \\
(n=21)\end{array}$} & SBP & 133.8 & 12.8 & 127.1 & 13.5 & $0.0232^{*}$ & 123.8 & 12.0 & $0.0012^{*}$ \\
\hline & DBP & 81.4 & 7.3 & 79.0 & 9.4 & 0.2135 & 76.2 & 6.7 & $0.0033^{*}$ \\
\hline & HR & 80.6 & 12.8 & 79.4 & 13.7 & 0.6219 & 79.5 & 14.6 & 0.6850 \\
\hline & $\% \mathrm{SpO}_{2}$ & 97.0 & 1.0 & 97.0 & 1.9 & 0.0744 & 97.0 & 0.7 & 0.5750 \\
\hline \multirow{4}{*}{$\begin{array}{c}\mathrm{NI} \\
(n=19)\end{array}$} & SBP & 117.9 & 8.5 & 114.7 & 9.0 & 0.0587 & 112.1 & 9.8 & $0.0076^{\star}$ \\
\hline & DBP & 76.3 & 5.0 & 74.2 & 6.1 & 0.1775 & 72.1 & 7.1 & $0.0277^{\star}$ \\
\hline & HR & 76.4 & 12.3 & 73.4 & 9.2 & 0.5861 & 72.7 & 9.7 & 0.2944 \\
\hline & $\% \mathrm{SpO}_{2}$ & 97.2 & 1.1 & 97.8 & 0.9 & 0.0663 & 97.9 & 0.8 & $0.0033^{*}$ \\
\hline
\end{tabular}

${ }^{*} p<0.05$, significant difference (Wilcoxon test). SD, standard deviation; T0, beginning of the study; T6, after 6 weeks of physical training; T12, after 12 weeks of physical training

Table 4: Analysis of post-exertion systolic blood pressure (SBP) and diastolic blood pressure (DBP), heart rate $(\mathrm{HR})$ and oxygen saturation $\left(\mathrm{SpO}_{2}\right)$ in participants with Chagas disease (CHD), and systemic arterial hypertension (SAH) and normal individuals (NI)at T0, T6, and T12

\begin{tabular}{|c|c|c|c|c|c|c|c|c|c|}
\hline Group & $\begin{array}{c}\text { Post-exertion } \\
\text { variable }\end{array}$ & $\begin{array}{r}7 \\
\text { (mear }\end{array}$ & SD) & (mear & SD) & $p$ & $\begin{array}{r}\mathrm{T} \\
\text { (mear }\end{array}$ & SD) & $P$ \\
\hline $\begin{array}{l}\text { CHD } \\
(n=16)\end{array}$ & $\begin{array}{c}\text { SBP } \\
\mathrm{DBP} \\
\mathrm{HR} \\
\% \mathrm{SpO}_{2}\end{array}$ & $\begin{array}{l}127.5 \\
81.9 \\
80.4 \\
97.9\end{array}$ & $\begin{array}{c}15.3 \\
9.8 \\
13.0 \\
1.2\end{array}$ & $\begin{array}{l}127.5 \\
81.3 \\
81.5 \\
97.9\end{array}$ & $\begin{array}{c}10.6 \\
7.2 \\
12.2 \\
1.2\end{array}$ & $\begin{array}{l}0.9326 \\
0.7531 \\
0.6101 \\
0.9999\end{array}$ & $\begin{array}{l}123.8 \\
80.0 \\
80.9 \\
98.1\end{array}$ & $\begin{array}{c}9.6 \\
7.3 \\
13.5 \\
1.0\end{array}$ & $\begin{array}{l}0.1688 \\
0.4008 \\
0.8657 \\
0.0678\end{array}$ \\
\hline $\begin{array}{c}\text { SAH } \\
(n=21)\end{array}$ & $\begin{array}{c}\text { SBP } \\
\text { DBP } \\
\mathrm{HR} \\
\% \mathrm{SpO}_{2}\end{array}$ & $\begin{array}{l}129.0 \\
80.5 \\
85.8 \\
97.5\end{array}$ & $\begin{array}{c}13.0 \\
8.0 \\
15.7 \\
1.2\end{array}$ & $\begin{array}{l}124.8 \\
77.6 \\
83.0 \\
97.8\end{array}$ & $\begin{array}{c}12.5 \\
9.4 \\
15.7 \\
0.8\end{array}$ & $\begin{array}{l}0.0934 \\
0.1955 \\
0.1213 \\
0.2367\end{array}$ & $\begin{array}{l}121.9 \\
75.2 \\
83.8 \\
97.9\end{array}$ & $\begin{array}{c}11.2 \\
6.8 \\
11.8 \\
0.6\end{array}$ & $\begin{array}{c}0.0035^{\star} \\
0.0033^{\star} \\
0.7323 \\
0.1744\end{array}$ \\
\hline $\begin{array}{c}\text { NI } \\
(n=19)\end{array}$ & $\begin{array}{c}\text { SBP } \\
\text { DBP } \\
\mathrm{HR} \\
\% \mathrm{SpO}_{2}\end{array}$ & $\begin{array}{l}116.3 \\
75.3 \\
78.7 \\
98.1 \\
\end{array}$ & $\begin{array}{l}6.8 \\
5.1 \\
8.0 \\
0.9\end{array}$ & $\begin{array}{l}116.3 \\
75.3 \\
77.3 \\
98.3 \\
\end{array}$ & $\begin{array}{l}9.6 \\
5.1 \\
8.1 \\
0.7\end{array}$ & $\begin{array}{l}0.9999 \\
0.9999 \\
0.2665 \\
0.2367 \\
\end{array}$ & $\begin{array}{l}111.1 \\
72.1 \\
75.6 \\
98.4 \\
\end{array}$ & $\begin{array}{l}8.8 \\
7.1 \\
9.6 \\
0.8\end{array}$ & $\begin{array}{c}0.0076^{\star} \\
0.0277^{\star} \\
0.0619 \\
0.0587 \\
\end{array}$ \\
\hline
\end{tabular}

${ }^{*} p<0.05$, significant difference (Wilcoxon test). SD, standard deviation; T0, beginning of the study; T6, after 6 weeks of physical training; T12, after 12 weeks of physical training 
Inter-group comparisons revealed that serum IL10 levels were significantly higher in the CHD group compared with the $\mathrm{SAH}$ and $\mathrm{NI}$ groups at T0, T6, and T12. Serum IFN-y levels were also higher in the CHD group compared with the SAH
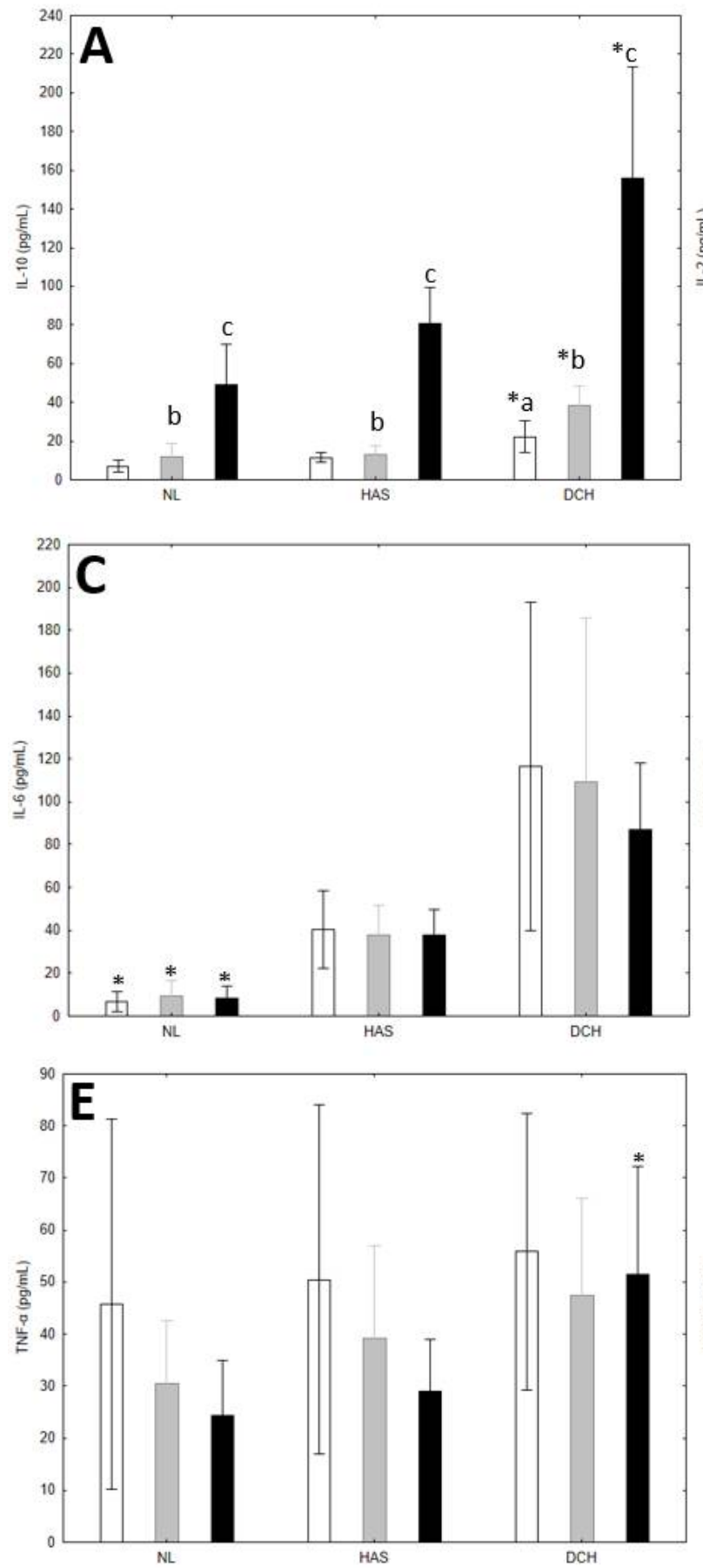

group at T0, T6, and T12 and compared with the $\mathrm{NI}$ group at T12. TNF- $\alpha$ levels were significantly higher in the $\mathrm{CH}$ group compared with the $\mathrm{NI}$ group at T12 (Figure 1).
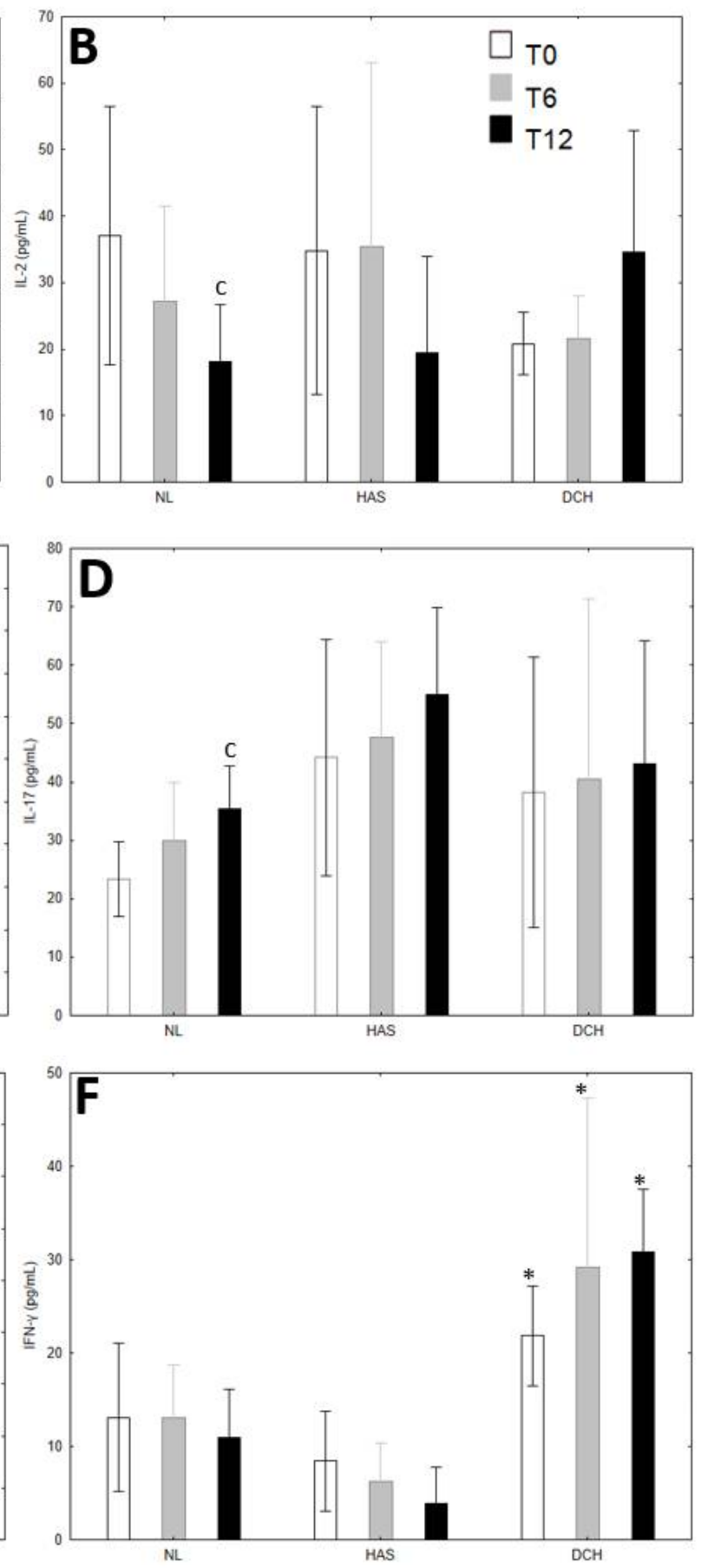

Figure 1: Serum levels of the cytokines IL-10 (A), IL-2 (B), IL-6 (C), IL-17 (D), TNF- $\alpha(E)$, INF-Y (F), in the groups with Chagas disease (CHD), and systemic arterial hypertension (SAH) and normal individuals (NI), at the beginning of the study (T0), after 6 weeks (T6) and 12 weeks (T12) of physical training ${ }^{\mathrm{a}} p<0.05$, significant difference between T0 and T6; ${ }^{\mathrm{b}} p<0.05$, significantly different between T6 and T12; ${ }^{\circ} p<0.05$, significant difference between T12 and T0 (paired Wilcoxon test for intragroup comparison), ${ }^{*} p<0.05$, significant difference (Wilcoxon test for intergroup comparisons). 


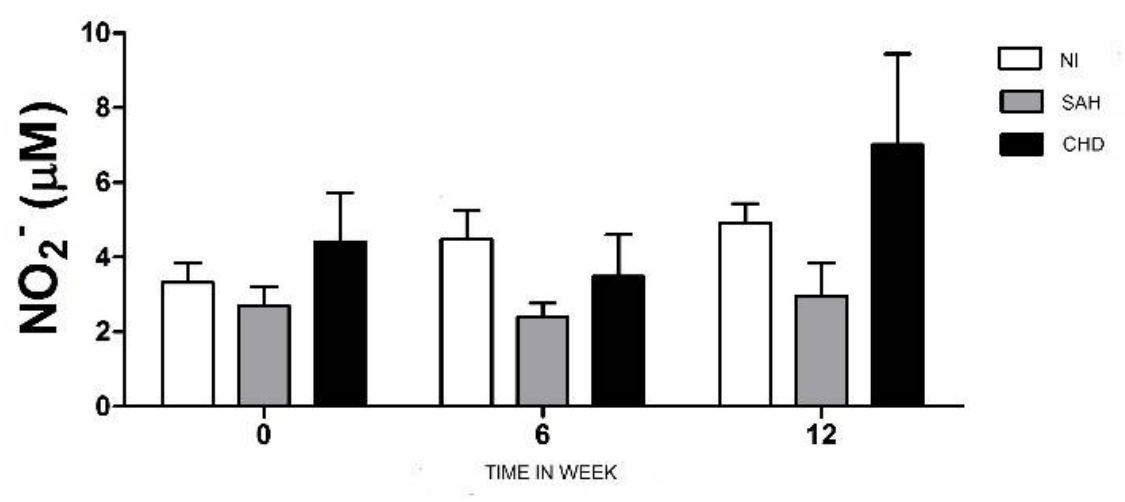

Figure 2: Serum levels of nitric oxide (NO), in the groups with Chagas disease (CHD), and systemic arterial hypertension $(\mathrm{SAH})$ and normal individuals $(\mathrm{NI})$, at the beginning of the study $(0)$, after 6 weeks $(6)$ and 12 weeks (12) of physical training

IL-6 levels were significantly lower in the $\mathrm{NI}$ group compared with $\mathrm{CHD}$ and $\mathrm{SAH}$ groups at T0, T6, and T12. No significant differences in IL2 or IL-17 levels were observed (data not shown). Physical training did not alter NO production in any of the groups (Figure 2).

\section{DISCUSSION}

In the present study, the $\mathrm{CHD}, \mathrm{SAH}$, and $\mathrm{NI}$ groups performed the 6MWT before and after a 12-week physical training program, to evaluate their performance and cardiopulmonary functional capacity. A significant increase in the distance traveled in the 6MWT was observed after the 12-week physical training program in all three groups, and most of the participants did not report physical exertion at the end of the test. These results demonstrated good performance in the 6MWT and improved functional capacity in the participants after regular 12-week moderateintensity physical training.

Inter-group comparisons indicated no significant differences in the distance traveled in the 6MWT or perceived exertion. All of the participants had a good prognosis, in which they traveled a distance $\geq 350 \mathrm{~m}$ and were able to complete the test [15]. The good performance of the participants with $\mathrm{CHD}$ and $\mathrm{SAH}$ may be associated with NYHA functional classes I and II. Functional capacity and the distance traveled in the 6MWT in Chagas disease carriers are associated with the severity of cardiopathy [16]. These results indicate that the participants did not present functional impairment and thus had a lower risk of death because they were able to walk a longer distance than the considered cutoff value $(522 \mathrm{~m})$ for patients with $\mathrm{CHD}$ and heart failure $[16,17]$ and a longer distance than patients of both genders with mild $\mathrm{SAH}$ [1].
The 12-week physical training program significantly improved the participants' blood pressure in the first exercise session at T6 and at T12. In the CHD and SAH groups, a significant reduction of SBP was observed in the first physical exercise session. According to Teixeira [19], after a single exercise session, blood pressure was decreased compared with prior values, and this decrease was maintained for an average of 1-2 $h$, thus characterizing a subacute response to exercise. This response begins immediately after the end of the exercise session and may last for 3-4 h. Decreases in the adrenergic response, cardiac output, postexertion plasma volume, and thermodilatation are subacute responses to exercise. The reductions of pre-exertion SBP in the SAH group at T6, pre- and post-exertion SBP and postexertion DBP in the CHD group between T6 and $\mathrm{T} 12$, and post-exertion SBP in the $\mathrm{NI}$ group between T6 and T12 are consistent with other studies that performed 6-10 week short term physical training [8].

At T12, reductions of pre and post-exertion SBP and in post-exertion DBP were observed, corroborating a previous study that conducted physical training for 12 weeks [8]. A significant decrease in pre-exertion SBP was observed in all three groups, and a decrease in pre-exertion DBP was observed in the SAH and $\mathrm{NI}$ groups, demonstrating the beneficial effects of physical exercise. Other authors also reported favorable effects of mild- or moderate-intensity exercise in reducing blood pressure in humans [8] and animals [9]. Such physical exercise induces structural cardiovascular remodeling, and is recommended for the prevention and treatment of SAH. Regular aerobic physical activity(e.g., walking) for at least 30 min three times per week reduces SBP by $4-11 \mathrm{mmHg}$, which returns to 
pre-exercise values when physical activity is interrupted [20].

Reductions of DBP of only $2 \mathrm{mmHg}$ can decrease the risk of comorbidities and mortality associated with hypertension, and physical exercise is indicated for patients with cardiovascular disease and mild cardiopathy. Such physical exercise has important health benefits. It lower risk factors, potentiates the efficacy of drug treatments, reduces the incidence of sudden death, improves quality of life, improves prognosis, and increases survival [20].

The pathogenesis of the chronic phase of Chagas disease is associated with host- and parasite, related factors, such as genetic constitution and the immune response. In the present study, the dynamics of IL-10 secretion were different in individuals with $\mathrm{CHD}$, which was likely attributable to the parasite-host relationship. A significant increase in IL-10 levels was observed after 6 and 12 weeks of exercise in the CHD group. In the SAH and $\mathrm{NI}$, groups, the increase in IL-10 levels was only observed after 12 weeks of exercise. Other authors have reported that regular, long-term, moderateintensity physical training induces restorative stimulation of the immune system, including increases in antiinflamatory cytokines (e.g., IL-10 and IL-4) and other cytokines (e.g., IL-5, IL-8, IL13, IL-15, IL-1ra, and tumor growth factor), which reduce the occurrence of infection [6,9]. The antiinflammatory cytokines IL-4 and IL-10 attenuate the inflammatory response by decreasing the proinflammatory cytokines and suppressing monocyte activation. Moderate physical training improved the response to infection, decreased the parasite peak, and increased survival in mice that were infected with T. cruzi [9].

IL-10 is important in regulating the immune response, inflammatory response, and tissue damage, through its ability to "turn off" the production of inflammatory cytokines by $\mathrm{T}$ lymphocytes [21]. In the present study, serum IL10 levels were elevated in the CHD group. Elevations of this cytokine were also observed in asymptomatic patients, suggesting that $\mathrm{IL}-10$ is part of a regulated immune response in patients without cardiomyopathy [21], and the presence of this cytokine is indicative of a good prognosis. Exogenous supplementation with $\mathrm{IL}-10$ in Chagas disease can be useful for controlling myocarditis [22], in addition to controlling cardiac fibrosis. In the present study, regular moderateintensity physical exercise for 12 weeks significantly increased IL-10 levels in the CHD, $\mathrm{SAH}$, and $\mathrm{NI}$ groups.

Another interesting result was the significant difference in the serum levels of the proinflammatory cytokines IL-2, IL-6, IL-17 and TNF- $\alpha$ in the NI group after 12 weeks of physical training. These cytokines promote the activation of the inflammatory process, thereby eliminating pathogens, activating macrophages, Natural Killer cells, T cells, and B cells, and inducing immunoglobulin proliferation. We observed significant increases in IL-17 and IL-6 levels. IL-6 is known as an "exercise factor", that regulates the acute phase during physical exercise [7].Increases in IL-6 levels in response to physical exercise can play an antiinflammatory role, especially by inhibiting TNF- $\alpha$ production and stimulating the synthesis of antiinflammatory cytokines [7]. Increases in IL-17 levels were also observed in the CHD group. Individuals with Chagas heart disease have lower IL-17 expression. High IL-17 expression is associated with better heart function and may be a protective factor in preventing myocardial damage in humans with Chagas disease [23].

Inter-group comparisons revealed elevations of $\mathrm{IL}-10$ and IFN- $\gamma$ levels in the CHD group compared with the SAH and $\mathrm{NI}$ groups. In the acute phase of infection, IFN- $y$ acts in concert with TNF- $\alpha$ to induce macrophage activation, and consequently $\mathrm{NO}$ production to eliminate the parasite $[22,23]$. In present study, the CHD, group had significantly higher TNF-a levels than the $\mathrm{NI}$ group at T12, which is consistent with other studies that reported high levels of TNF- $\alpha$ in patients with Chagas disease compared with healthy individuals [24]. The increase in TNF- $\alpha$ levels is related to the evolution of Chagas disease from the asymptomatic form to the symptomatic form, and is associated with the course and severity of chronic Chagas heart disease, suggesting its involvement in the formation of chronic inflammation and cardiac lesions [24].

Guedes et al. [25] reported that patients with moderate or severe cardiopathy had higher IFN-y and TNF- $\alpha$ expression and lower levels of IL-10 compared with patients with mild or no cardiopathy. Additionally, patients with a high risk of death exhibited lower levels of IL-10 and higher levels of IFN- $\gamma$, TNF- $\alpha$, and inducible nitric oxide synthase, reflecting higher NO production, than patients with a low risk of death. In the present study, the immune response in participants with Chagas disease was significantly different from the other two groups, in which they presented elevations of IL-10 levels 
and no increase in the production of $\mathrm{NO}$, thus indicating a lower disease severity and lower risk of death. There are no markers that can predict the risk of developing cardiopathy in individuals with Chagas disease. The wide variation in the clinical course of this disease is attributable to complex host-parasite interactions. Symptomatic chronic infection induces an immune-type inflammatory response, with increases in the production of IL-2, IL-6, TNF- $\alpha$, and IFN- $\alpha$ and decreases in the production of IL-4. Asymptomatic infection of an undetermined phase is characterized by a more regulated immune response, with higher production of antiinflammatory cytokines (e,g., IL-10 and IL-4), that promote the regulation of the immune response, prevent immunological damage and provide the persistence of $T$. cruzi in tissue[2].

\section{Limitations of the study}

In the present study, no significant difference in IL-6 levels was observed between SAH and CHD groups. No significant difference in $\mathrm{NO}$ production between T0, T6, and T12 was observed in any of the groups, including the CHD group that presented the highest $\mathrm{NO}$ levels at all times tested compared with the other groups. This lack of observed differences may be attributable to the small sample size used in the study.

\section{CONCLUSION}

Regular moderate-intensity exercise is important for improving quality of life, by reducing blood pressure, preventing coronary and autoimmune disease and stimulating the production of antiinflammatory cytokines (e.g., IL-10). The CHD group presented good performance in the $6 \mathrm{MWT}$, in which they did not present a significant difference in distance traveled or perceived exertion compared with the SAH and NI groups. Significant decreases in SBP and DBP and a significant increase in antiinflammatory IL-10 levels were observed in all three groups after 12 weeks of physical training.

\section{DECLARATIONS}

\section{Acknowledgement}

The authors thank all of the subjects for their voluntary participation in this study.

\section{Conflict of Interest}

No conflict of interest associated with this work.

\section{Contribution of Authors}

The authors declare that this work was done by the authors named in this article and all liabilities pertaining to claims relating to the content of this article will be borne by them.

\section{Open Access}

This is an Open Access article that uses a funding model which does not charge readers or their institutions for access and distributed under the terms of the Creative Commons Attribution License (http://creativecommons.org/licenses/by 14.0) and the Budapest Open Access Initiative (http://www.budapestopenaccessinitiative.org/rea d), which permit unrestricted use, distribution, and reproduction in any medium, provided the original work is properly credited.

\section{REFERENCES}

1. World Health Organization. Chagas disease in Latin America: an epidemiological update based on 2010 estimates. Weekly Epidemiol Record 2015; 90: 33-44.

2. Cunha-Neto E, Nogueira LG, Teixeira PC, Ramasawmy R, Drigo SA, Goldberg AC, Fonseca FG, Bilate AM, Kalil $J$. Immunological and non-immunological effects of cytokines and chemokines in the pathogenesis of chronic Chagas disease cardiomyopathy. Mem Inst Oswaldo Cruz. 2009; 104 (Suppl 1): 252-258.

3. Vieira FC, de Melo Marinho PE, Brandão DC, Barbosa e Silva $O$. Respiratory muscle strength, the six-minute walk test, and quality of life in Chagas cardiomyopathy. Physiother Res Int 2014; 19(1): 8-15.

4. Lopes WS, Guedes TA, Araújo SM, Gomes ML. Comparison of blood pressure and heart frequency among women with and without Chagas disease submitted to physical training. Fiep Bull 2011; 81: 603607.

5. Dutra WO, Gollob KJ. Current concepts in immunoregulation and pathology of human Chagas disease. Curr Opin Infect Dis. 2008; 21(3): 287-292.

6. Silva FOC, Macedo DV. Exercício físico, processo inflamatório e adaptação: uma visão geral. Rev Bras Cineantropom Desempenho Hum 2011; 13(4): 320-328.

7. Mendes MFA, Wilson A, Nogueira GA, Cassarotti DJ, Araújo SM, Gomes ML. Atividade física aeróbia em mulheres com doença de Chagas. Fisioter Mov 2011; 24(4): 591-560.

8. Lopes WS, Cuman RKN, Guedes TA, Araújo SM. Exercício aeróbio reduz a hipertensão arterial de Mulheres com doença de Chagas. Rev Bras Med Esporte 2014; 20(2): 131-136.

9. Schebeleski-Soares C, Occhi-Soares RC, Franzoi-deMoraes SM, de Oliveira Dalalio MM, Almeida FN, Toledo MJO, and Araujo SM. Preinfection aerobic treadmill training improves resistance against

Trop J Pharm Res, February 2017; 16(2): 461 
Trypanosoma cruzi infection in mice. Appl Physiol Nutr Metab 2009; 34: 659-665.

10. Rondelli RR, Oliveira AN, Dal Corso S, Malaguti C. Uma atualização e proposta de padronização do teste de caminhada de seis minutos. Fisioter Mov 2009; 22(2): 249-259.

11. Ethics and research on human subjects: International guidelines. J Med Ethics. 1995; 21(6): 363-364. PMCID: PMC1376838.

12. American Thoracic Society Committee on Proficiency Standards for Clinical Pulmonary Function Laboratories. ATS Statement: guidelines for the six-minute walk test. Am J Respir Crit Care Med 2002; 166(1): 111-117.

13. Regenga MM. Fisioterapia em Cardiologia da UTI à Reabilitação. 1a ed. São Paulo: Editora Roca, 2000.

14. Panis C, Victorino VJ, Herrera ACSA, Freitas LF, De Rossi $T$, Campos FC, Simão NA, Barbosa DS, PingeFilho $P$, Cecchini $R$, Cecchini AL. Differential oxidative status and immune characterization of the early and advanced stages of human breast cancer. Br Cancer Res Treat 2012; 133(3): 881-888.

15. Cahalin LP, Mathier MA, Semigran MJ, Dec GW, Di Salvo TG. The six-minute walk test predicts peak oxygen uptake and survival in patients with advanced heart failure. Chest 1996; 110: 325-332.

16. Sousa $L$, Botoni FA, Britto RR, Rocha MO, Teixeira $A L$ $J r$, Teixeira $M M$, Reis $A M$, Oliveira BMR, Ribeiro $A L$. Six-minute walk test in Chagas cardiomyopathy. Int $\mathrm{J}$ Cardiol 2008; 125: 139-141.

17. Costa HS, Lima MMO, de Sousa GR, de Souza AC, Alencar MCN, Nunes MCP, Rocha MOC. Functional capacity and risk stratification by the six-minute walk test in Chagas heart disease: comparison with cardiopulmonary exercise testing. Int J Cardiol 2014; 177(2): 661-663.
18. Ramos RA, Ferreira AS. Capacidade funcional de adultos com hipertensão avaliada pelo teste de caminhada de seis minutos: revisão sistemática. Fisioter Pesq 2014; 21(3): 257-263.

19. Teixeira JAC. Hipertensão arterial sistêmica e atividade física. Rev SOCERJ 2000; 13(4): 24-30.

20. Sociedade Brasileira de Cardiologia; Sociedade Brasileira de Hipertensão; Sociedade Brasileira de Nefrologia. VI Diretrizes Brasileiras de Hipertensão. Arq Bras Cardiol. 2010; 95(1) Suppl.1: 1-51.

21. Vasconcelos RHT, Azevedo $E$ de AN, Diniz GTN, Cavalcanti $M$ da GA de $M$, de Oliveira $W \mathrm{Jr}$, de Morais CNL, de M Gomes Y. de M. Interleukin-10 and tumour necrosis factor-alpha serum levels in chronic Chagas disease patients. Parasite Immunol. 2015; 37: 376-379.

22. Oft M. IL-10: master switch from tumor-promoting inflammation to antitumor immunity. Cancer Immunol Res. 2014; 2: 194-199.

23. Magalhães $L M D$, Villani $F N A$, do Carmo $P$ Nunes $M$, Gollob KJ, Rocha MOC, Dutra WO. High interleukin 17 expression is correlated with better cardiac function in human Chagas disease. J Infect Dis 2013; 207: 661665.

24. Criado L, Flórez O, Martín J, González Cl. Genetic polymorphisms in TNFA/TNFR2 genes and Chagas disease in a Colombian endemic population. Cytokine. 2012; 57(3): 398-401.

25. Guedes $P M M$, de Andrade CM, Nunes DF, de Sena Pereira N, Queiroga TBD, Machado-Coelho GLL, Nascimento MSL, Do-Valle-Matta MA, da Câmara ACJ, Chiari E, Galvão LMC. Inflammation enhances the risks of stroke and death in chronic Chagas disease patients. PLoS Negl Trop Dis. 2016; 10(4): 0004669. 